\title{
Adição de óleo de palma na dieta sobre a lipidemia e a qualidade do sêmen de bubalinos (Bubalus bubalis)
}

\author{
[Addition of palm oil to diet on serum lipid profile and seminal quality \\ of buffaloes (Bubalus bubalis)]
}

\author{
G.R. Silva ${ }^{1}$, A.R. Garcia ${ }^{2 *}$, C. Faturi ${ }^{3}$, J.B. Lourenço Junior ${ }^{4}$, B.S. Nahúm ${ }^{5}$, A.A. Gonçalves ${ }^{1}$, \\ P.R. Kawhage ${ }^{1}$, L.H.M. Silva ${ }^{6}$, A.M.C. Meneses $^{3}$

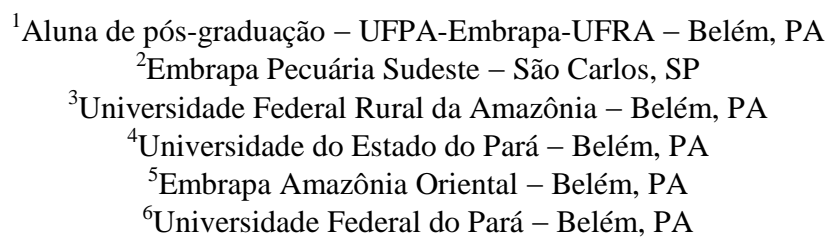

\section{RESUMO}

O estudo visou investigar o efeito da suplementação dietética com óleo de palma sobre o perfil sérico lipídico e as características seminais de touros bubalinos (Bubalus bubalis), bem como suas correlações. Doze touros foram alocados no Grupo CONT $(n=5)$ ou Grupo ÓLEO $(n=7)$ e receberam alimentação isoproteica composta por silagem de milho e concentrado (milho triturado, farelo de trigo e ureia), com proporção volumoso/concentrado de 50\%, durante 130 dias (Períodos 1 e 2). Diferencialmente, óleo de palma foi adicionado ao concentrado $(2 \% \mathrm{MS})$ do Grupo ÓLEO. Sêmen e sangue foram colhidos quinzenalmente. Houve aumento nas concentrações séricas de colesterol, HDL e lipídios totais nos animais do Grupo ÓLEO, enquanto o período influenciou nas taxas de colesterol, LDL, lipídios totais e VLDL $(\mathrm{P}<0,05)$. Houve decréscimo no turbilhonamento e discreta redução na integridade de membranas nos animais do Grupo ÓLEO $(\mathrm{P}<0,05)$. Correlações significativas foram encontradas entre triglicerídeos e defeitos menores $(\mathrm{r}=-0,412 ; \mathrm{P}=0,006)$, LDL e defeitos totais $(\mathrm{r}=-0,333 ; \mathrm{P}=0,030)$, lipídios totais e defeitos menores $(\mathrm{r}=-0.366 ; \mathrm{P}=0,017)$, lipídios totais e defeitos totais $(\mathrm{r}=-0.309 ; \mathrm{P}=0,046)$, e VLDL e viabilidade espermática $(\mathrm{r}=0,381 ; \mathrm{P}=0,012)$, apontando efeitos positivos da maior lipidemia na morfologia e na viabilidade espermática. O uso de óleo de palma alterou o perfil lipídico sérico, mas não favoreceu per se os parâmetros seminais relacionados com o potencial de fertilidade dos touros.

Palavras-chave: búfalo, óleo de palma, perfil sérico, sêmen

\begin{abstract}
The study aimed to investigate the effect of dietary supplementation with palm oil on serum lipid profile, the seminal characteristics of buffaloes (Bubalus bubalis) and the correlations between them. Twelve bulls were divided into Group CONT $(n=5)$ or Group OIL $(n=7)$. Animals in both groups were fed with isoproteic diets composed of corn silage and concentrated (ground corn, wheat bran and urea), with 50\% forage/concentrate ratio, during 130 days (Periods 1 and 2). Palm oil (2\%DM) was added to diet offered to Group OIL. Semen and blood samples were collected every two weeks. Increased serum levels of cholesterol, HDL and total lipids were observed for Group OIL, while the period influenced on cholesterol, LDL, total lipids and VLDL $(P<0,05)$. Treatment decreased gross motility $(P<0.05)$ and slightly reduced sperm membrane integrity $(P<0.05)$ in animals of Group OIL. There were significant correlations between triglycerides and minor defects $(r=-0.412, P=0.006)$, LDL and total defects $(r=-$ 0.333, $P=0.030)$, total lipids and minor defects $(r=-0.366, P=0.017), V L D L$ and spermatic viability $(r=0.381, P=0.012)$, and total lipids and totals defects $(r=-0.309, P=0.046)$, highlighting positive effects
\end{abstract}

Recebido em 31 de outubro de 2012

Aceito em 17 de julho de 2013

*Autor para correspondência (corresponding author)

E-mail: alexandre.garcia@embrapa.br 
of higher lipid serum levels on sperm morphology and viability. The incorporation of palm oil in the diet altered the serum lipid profile, but it showed no positive effect on seminal parameters related to the potential of bull fertility.

Keywords: buffalo, palm oil, lipids, serum profile, semen

\section{INTRODUÇÃO}

Diferentes tipos de gorduras têm sido utilizados na dieta de ruminantes, na tentativa de melhorar sua função reprodutiva, com destaque para os ácidos graxos derivados de plantas e sementes oleaginosas (Adeel et al., 2009). O óleo de palma, também conhecido como óleo de dendê, é retirado do mesocarpo do dendê (Elaeis guineensis Jacq.) e representa hoje pouco mais de um terço do total de óleos consumidos no mundo. Recentemente, o Brasil vem investindo na franca ampliação das áreas plantadas com dendê, com o objetivo de produzir óleo tanto para uso alimentício quanto para a fabricação de biocombustíveis. Assim, o aproveitamento de produtos gerados por essas agroindústrias pode ser uma alternativa para alimentação de ruminantes, pois o fruto é disponível e industrializado o ano todo.

O aumento das concentrações lipídicas na dieta de ruminantes pode ocasionar elevação nos parâmetros séricos de colesterol, triglicerídeos, lipoproteínas de alta densidade (HDL), lipoproteínas de baixa densidade (LDL), lipoproteínas de muito baixa densidade (VLDL) e lipídios totais (Ranjan et al., 2012). Sabe-se, porém, que, quando os bubalinos são criados sob diferentes condições ambientais e de manejo, variações podem ocorrer, tornando os parâmetros séricos relatados na literatura inconsistentes para generalizações (Nalavade et al., 2002; Nikam et al., 2005).

A suplementação alimentar com fontes lipídicas desencadeia eventos metabólicos importantes para a reprodução e pode interferir em eventos relacionados à fertilização, como a maturação e a capacitação espermática, nos quais ocorrem modificações lipídicas na membrana plasmática (Moreau e Manjunath, 2000). Por isso, o maior aporte dietético de lipídios pode, hipoteticamente, trazer benefícios ao desempenho reprodutivo de machos, pela elevação dos aspectos quantitativos e qualitativos do sêmen, favorecendo a fertilidade dos animais em monta natural, além de permitir produção de um número maior de doses de sêmen congelado por ejaculado. Por isso, o estudo teve como objetivo avaliar o efeito da incorporação do óleo de palma na dieta sobre o perfil lipídico sérico e sua relação com as características físicas e morfológicas do sêmen de touros bubalinos (Bubalus bubalis) mantidos em confinamento.

\section{MATERIAIS E MÉTODOS}

O trabalho foi realizado na Embrapa Amazônia Oriental, Belém, Pará ( $\left.1^{\circ} 43^{\prime} \mathrm{S}, 48^{\circ} 44^{\prime} \mathrm{W}\right)$. Como doadores de sêmen, foram utilizados 12 touros

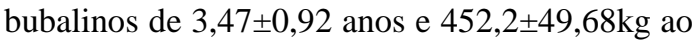
início do experimento, previamente selecionados quanto às suas características físicas, clínicas, idade, peso e circunferência escrotal. Como critério balizador, todos os animais apresentavam avaliação andrológica positiva antes do início do ensaio (Vale, 2002). O experimento compreendeu 130 dias, que incluíram o tempo para adaptação dos animais ao manejo do confinamento (14 dias) e dois períodos consecutivos de 58 dias (P1 e P2), definidos para constatação do efeito das dietas ao longo do tempo, em função da fisiologia reprodutiva do touro bubalino. Cada período correspondeu ao tempo médio requerido para ocorrência de uma espermatogênese completa, somado ao tempo necessário para o trânsito seminal, armazenamento epididimário e ejaculação (Sharma e Gupta, 1980). Os procedimentos adotados foram aprovados pelo Comitê de Ética em Pesquisa com Animais de Experimentação da Universidade Federal do Pará (CEPAE/UFPA-Parecer BIO042-12).

Os animais foram mantidos em regime de confinamento em dois lotes (Grupo Controle CONT, n=5, e Grupo Tratamento - ÓLEO, n=7) e receberam diariamente dieta composta por forragem e concentrado. Como diferencial, os animais do Grupo ÓLEO receberam suplementação energética com óleo de palma, referente a $2 \%$ da dieta, com base na matéria seca (Tab. 1), o qual foi adicionado à fração do concentrado. 
Tabela 1. Composição das dietas enriquecidas (ÓLEO) ou não (CONT) com óleo de palma a $2 \%$ da matéria seca, fornecidas a touros bubalinos em regime regular de colheita de sêmen

\begin{tabular}{ccc}
\hline \multirow{2}{*}{ Ingredientes } & \multicolumn{2}{c}{ Grupos* } \\
\cline { 2 - 3 } & Cont & Óleo \\
\hline Silagem de & 50,00 & 50,00 \\
Milho (\%) & & \\
Farelo de Trigo & 19,90 & 19,25 \\
$(\%)$ & & \\
Milho Triturado & 29,50 & 28,00 \\
$(\%)$ & & \\
Ureia (\%) & 0,60 & 0,70 \\
Oleo de Palma & - & 2,05 \\
$(\%)$ & & \\
\hline Composição & & \\
\hline PB (\%) & 12,37 & 12,33 \\
EE (\%) & 3,47 & 5,43 \\
FDN (\%) & 32,12 & 31,51 \\
FDA (\%) & 23,95 & 23,59 \\
MS (\%) & 61,04 & 59,13 \\
\hline
\end{tabular}

*PB: proteína bruta; EE: extrato etéreo; FDN: fibra em detergente neutro; FDA: fibra em detergente ácido; MS: matéria seca. Cont: concentrado controle; Óleo: concentrado enriquecido com óleo de palma (2\%MS).

As rações foram formuladas de acordo com Paul e Lal (2010), sendo isoproteicas $(\sim 12 \%$ de proteína bruta), e foram administradas duas vezes ao dia, em cochos coletivos, de forma a promover consumo ad libitum aos animais. Diariamente, pela manhã, foram removidas e pesadas as sobras do dia anterior, para cálculo de consumo e ajustes da quantidade ofertada. Os animais foram individualmente pesados a cada 15 dias, após jejum alimentar de 12 horas. Os animais tiveram acesso irrestrito à água em bebedouro automático e a sal mineral em cocho coberto.

A extração lipídica dos ingredientes da rações foi realizada de acordo com Bligh e Dyer (1959), e o perfil lipídico foi obtido por cromatografia gasosa dos ésteres metílicos de ácidos graxos (FAMEs) e ionização de chama (CP 3380, equipado com CP-Sil 88 de $60 \mathrm{~m}$ x $0,25 \mathrm{~mm}$, Varian Analytical Instruments, Walnut Creek, EUA). Cada amostra FAME foi analisada em triplicata (Rodrigues et al., 2010). Os perfis lipídicos das dietas estão expressos na Tab. 2.
Tabela 2. Perfil lipídico das dietas fornecidas a touros bubalinos, compostas por silagem de milho, farelo de trigo, milho triturado e ureia, enriquecidas (ÓLEO) ou não (CONT) com óleo de palma a $2 \%$ da matéria seca

\begin{tabular}{lccc}
\multicolumn{1}{c}{ Ácidos graxos } & & \multicolumn{2}{c}{ Grupos* } \\
\cline { 1 - 1 } Saturados & & $\begin{array}{c}\text { Cont } \\
(\%)\end{array}$ & $\begin{array}{c}\text { Óleo } \\
(\%)\end{array}$ \\
\hline C8:0(Caprílico) & & 0,05 & 0,05 \\
C10:0 (Cáprico) & & 0,05 & 0,05 \\
C12:0 (Láurico) & & 0,17 & 0,17 \\
C14:0 (Mirístico) & & 0,27 & 0,26 \\
C16:0 (Palmítico) & & 16,25 & 16,93 \\
C18:0 (Esteárico) & & 1,51 & 2,61 \\
C20:0 (Araquídico) & & 1,37 & 1,36 \\
\cline { 1 - 1 } Insaturados & & & \\
\cline { 1 - 1 } C16:1 (Palmitoleico) & & 0,22 & 0,22 \\
C18:1n9 (Oleico) & & 36,18 & 36,38 \\
C18:2n6 (Linoleico) & & 41,96 & 40,90 \\
C18:3n3 (Linolênico) & & 0,39 & 0,38 \\
Não detectados & & 0,58 & 0,69 \\
\hline \multicolumn{1}{c}{ Total } & & 100,00 & 100,00 \\
\hline
\end{tabular}

*Cont: concentrado controle; Óleo: concentrado enriquecido com óleo de palma (2\%MS).

O sangue foi coletado quinzenalmente, centrifugado para remoção do soro e armazenado a $-20^{\circ} \mathrm{C}$. As coletas $(n=114)$ ocorreram pela manhã, após jejum de 12 horas, para evitar interferência pós-prandial nos valores lipêmicos. A avaliação do colesterol foi enzimática, com qualidade analítica de erro total $\leq 9,0 \%$, bias $\leq 3,0 \%$ e $C V \leq 3,0 \%$ (Colesterol Liquiform ${ }^{\circledR}$, Colesterol HDL $\AA$ e Triglicérides Liquiform $®$; Labtest Diagnóstica, Brasil). O valor de LDL foi obtido com uso da equação Colesterol LDL = Colesterol Total - (HDL + VLDL). Já a fração VLDL foi obtida pela fórmula (Triglicerídeos $(\mathrm{mg} / \mathrm{dL}) / 5)$, enquanto os lipídios totais representaram a soma de triglicerídeos e colesterol total (Friedewald, 1972). As análises foram realizadas em analisador bioquímico semiautomático microprocessado (TP-Analyzer Basic ${ }^{\circ}$, Thermoplate, China).

Os animais passaram por colheitas de sêmen quinzenais, sendo realizadas, no mínimo, nove colheitas por animal $(n=117)$. Os touros foram previamente higienizados, e o sêmen foi colhido por vagina artificial. Imediatamente após a colheita, foram avaliados volume, $\mathrm{pH}$, turbilhonamento, motilidade progressiva, vigor e concentração espermática, conforme Vale (2002). A integridade da membrana plasmática 
dos espermatozoides foi avaliada pelo teste hiposmótico (solução de $0,735 \mathrm{~g}$ de citrato de sódio e $1,351 \mathrm{~g}$ de frutose para $100 \mathrm{~mL}$ de água destilada; $190 \mathrm{mOsm} / \mathrm{kg}$ ), com contagem e classificação de 200 espermatozoides (Khan e Ijaz, 2008). A viabilidade espermática foi determinada pela técnica de coloração com eosina-nigrosina, sendo contadas e classificadas 200 células por amostra, e o resultado expresso em porcentagem (Iqbal et al., 2010). A avaliação da morfologia espermática foi realizada em microscopia de contraste de fase sob aumento de 1.000X. Contaram-se 200 células por lâmina, as quais foram individualmente classificadas em defeitos maiores, menores e totais, sendo o resultado apresentado em porcentagem (Blom, 1973).

O delineamento experimental utilizado foi inteiramente ao acaso, com dois tratamentos, avaliados em dois períodos de 58 dias, em um arranjo fatorial $2 \times 2$. Os dados foram testados quanto à normalidade da distribuição pelo comando PROC univariate opção normal do SAS (Statistical..., 1993). Os dados que não apresentaram distribuição normal foram transformados empregando Log de 10. Os resultados foram submetidos à análise de variância (ANOVA), a fim de testar o efeito de tratamento, período e a interação entre os dois fatores. Realizou-se a comparação entre tratamentos pelo uso do teste F. Foi estabelecida, ainda, a correlação de Pearson entre as variáveis do lipidograma e as variáveis de parâmetros seminais. O nível de significância adotado para todas as análises foi de $5 \%(\mathrm{P}<0,05)$.

\section{RESULTADOS}

Os resultados do consumo diário, incluindo os tipos de ácidos graxos ingeridos nas dietas controle ou com inclusão de óleo de palma, estão apresentados na Tab. 3. Os valores séricos de triglicerídeos, colesterol total, HDL, LDL, VLDL e lipídios totais estão apresentados na Tab. 4. Observou-se que as concentrações de colesterol total, HDL e lipídios totais no Grupo ÓLEO foram mais elevadas $(\mathrm{P}<0,05)$. Considerando os períodos, houve diferença $(\mathrm{P}<0,05)$ nas variáveis lipídicas de $\mathrm{P} 1$ para $\mathrm{P} 2$, com exceção de triglicerídeos e HDL (Tab. 5).

Tabela 3. Consumo de matéria seca (MS), matéria seca por peso vivo (MSPV), proteína, extrato etéreo (EE) e ácidos graxos (AG) por búfalos alimentados com dietas sem e com inclusão de óleo de palma a $2 \%$ da matéria seca

\begin{tabular}{ccc}
\hline Consumo médio diário & Cont & Óleo \\
\hline MS (kg/animal) & $11,30 \pm 2,59$ & $11,35 \pm 2,91$ \\
MSPV (\%) & 2,0 & 2,03 \\
Proteína (kg/animal) & 1,36 & 1,37 \\
EE (kg/animal) & 0,39 & 0,62 \\
AG (g/animal) & & \\
\hline Saturados & & 0,31 \\
C8:0(Caprílico) & 0,20 & 0,31 \\
C10:0 (Cáprico) & 0,20 & 1,05 \\
C12:0 (Láurico) & 0,67 & 1,60 \\
C14:0 (Mirístico) & 1,06 & 104,34 \\
C16:0 (Palmítico) & 63,72 & 16,08 \\
C18:0 (Esteárico) & 5,92 & 8,38 \\
C20:0 (Araquídico) & 5,37 & $\mathbf{1 3 2 , 0 7}$ \\
Total Saturados & $\mathbf{7 7 , 1 4}$ & 1,35 \\
\hline Insaturados & & 224,21 \\
C16:1 (Palmitoleico) & 0,83 & 252,07 \\
C18:1n9 (Oleico) & 141,86 & 2,34 \\
C18:2n6 (Linoleico) & 164,53 & $\mathbf{4 7 9 , 9 7}$ \\
C18:3n3 (Linolênico) & 1,53 & $\mathbf{4 , 2 5}$ \\
Total Insaturados & $\mathbf{3 0 8 , 7 5}$ & $\mathbf{3 , 6 3}$ \\
Não detectados & $\mathbf{6 , 1 9}$ & \\
\hline Relação insaturados/saturados & $\mathbf{4 , 0 0}$ &
\end{tabular}

*Cont: concentrado controle; Óleo: concentrado enriquecido com óleo de palma (2\%MS). 
Tabela 4. Concentrações séricas de lipídios (Média $\pm D P$ ) de touros bubalinos alimentados com ração convencional ou enriquecida com óleo de palma a $2 \%$ da matéria seca

\begin{tabular}{|c|c|c|c|}
\hline \multirow{2}{*}{$\begin{array}{l}\text { Variáveis } \\
\text { (mg/dL) }\end{array}$} & \multicolumn{2}{|c|}{ Grupo } & \multirow{2}{*}{$\begin{array}{l}\text { CV } \\
(\%)\end{array}$} \\
\hline & Cont & Óleo & \\
\hline Triglicerídeos & $19,21 \pm 6,11 \mathrm{~A}$ & $18,32 \pm 4,75 \mathrm{~A}$ & 28,74 \\
\hline Colesterol & $61,44 \pm 16,00 \mathrm{~B}$ & $70,98 \pm 13,91 \mathrm{~A}$ & 21,41 \\
\hline HDL & $33,91 \pm 6,81 \mathrm{~B}$ & $41,16 \pm 7,90 \mathrm{~A}$ & 19,47 \\
\hline LDL & $23,25 \pm 14,94 \mathrm{~A}$ & $25,75 \pm 12,70 \mathrm{~A}$ & 52,37 \\
\hline VLDL & $4,27 \pm 1,37 \mathrm{~A}$ & $4,07 \pm 1,18 \mathrm{~A}$ & 29,77 \\
\hline Lipídios Totais & $80,65 \pm 17,22 B$ & $89,30 \pm 14,67 \mathrm{~A}$ & 17,74 \\
\hline
\end{tabular}

*Médias seguidas de letras maiúsculas diferentes na mesma linha diferem entre si pelo teste $\mathrm{F}(\mathrm{P}<0,05)$.

Tabela 5. Concentrações séricas de lipídios (Média \pm DP) de touros bubalinos alimentados com ração convencional ou enriquecida com óleo de palma a $2 \%$ da matéria seca, por períodos experimentais

\begin{tabular}{|c|c|c|c|}
\hline \multirow{2}{*}{$\begin{array}{l}\text { Variáveis } \\
\text { (mg/dl) }\end{array}$} & \multicolumn{2}{|c|}{ Período } & \multirow{2}{*}{$\begin{array}{l}\text { CV } \\
(\%)\end{array}$} \\
\hline & P1 & $\mathrm{P} 2$ & \\
\hline Triglicerídeos & $18,22 \pm 4,29 \mathrm{~A}$ & $19,28 \pm 6,43 \mathrm{~A}$ & 28,74 \\
\hline Colesterol & $63,58 \pm 17,53 \mathrm{~B}$ & $71,37 \pm 11,17 \mathrm{~A}$ & 21,41 \\
\hline HDL & $38,60 \pm 8,82 \mathrm{~A}$ & $37,62 \pm 7,54 \mathrm{~A}$ & 19,47 \\
\hline LDL & $20,58 \pm 15,85 \mathrm{~B}$ & $29,90 \pm 7,74 \mathrm{~A}$ & 52,37 \\
\hline VLDL & $4,40 \pm 1,19 \mathrm{~A}$ & $3,86 \pm 1,28 \mathrm{~B}$ & 29,77 \\
\hline Lipídios Totais & $81,80 \pm 18,00 \mathrm{~B}$ & $90,65 \pm 12,29 \mathrm{~A}$ & 17,74 \\
\hline
\end{tabular}

*Médias seguidas de letras maiúsculas diferentes na mesma linha diferem entre si pelo teste $\mathrm{F}(\mathrm{P}<0,05)$.

A dieta contendo óleo de palma não afetou $(\mathrm{P}>0,05)$ o volume, $\mathrm{pH}$, motilidade, vigor, viabilidade espermática e defeitos espermáticos do sêmen (Tab. 6). Em contrapartida, touros do
Grupo CONT apresentaram turbilhonamento espermático e integridade de membrana plasmática superiores aos do Grupo ÓLEO $(\mathrm{P}<0,05)$.

Tabela 6. Avaliação dos parâmetros seminais de touros bubalinos alimentados com ração convencional ou enriquecida com óleo de palma a $2 \%$ da matéria seca

\begin{tabular}{cccc}
\hline \multirow{2}{*}{ Variáveis } & \multicolumn{2}{c}{ Grupo } & \multirow{2}{*}{$\operatorname{cv}(\%)$} \\
\cline { 2 - 3 } & Cont & Óleo & 42,87 \\
Volume (mL) & $3,71 \pm 1,23 \mathrm{~A}$ & $3,61 \pm 1,74 \mathrm{~A}$ & 6,4 \\
pH (1-14) & $6,26 \pm 0,41 \mathrm{~A}$ & $6,37 \pm 0,39 \mathrm{~A}$ & 25,72 \\
Turbilhonamento (0-5) & $2,85 \pm 0,56 \mathrm{~A}$ & $2,38 \pm 0,82 \mathrm{~B}$ & 23,88 \\
Motilidade Progressiva (\%) & $59,10 \pm 11,38 \mathrm{~A}$ & $54,78 \pm 16,06 \mathrm{~A}$ & 13,18 \\
Vigor (0-5) & $3,15 \pm 0,46 \mathrm{~A}$ & $3,06 \pm 0,38 \mathrm{~A}$ & 22,19 \\
Viabilidade Espermática (\%) & $68,18 \pm 10,59 \mathrm{~A}$ & $61,72 \pm 16,70 \mathrm{~A}$ & 41,92 \\
Defeitos Totais (\%) & $20,43 \pm 9,63 \mathrm{~A}$ & $19,20 \pm 7,45 \mathrm{~A}$ & 15,73 \\
Integridade de Membrana - HOS (\%) & $72,34 \pm 8,64 \mathrm{~A}$ & $63,26 \pm 12,05 \mathrm{~B}$ & \\
\hline
\end{tabular}

*Médias seguidas de letras maiúsculas diferentes na mesma linha diferem entre si pelo teste $\mathrm{F}(\mathrm{P}<0,05)$.

Observou-se a interação entre o efeito da dieta e período experimental sobre os resultados de concentração espermática. Enquanto no Grupo CONT os animais não apresentaram diferenças significativas nos valores de concentração espermática do P1 para o P2 (1.472,60 versus $1.641,45 \times 10^{6} \mathrm{sptz} / \mathrm{mL}$ ), os animais do Grupo ÓLEO tiveram redução de $25 \%$ nesse parâmetro, do P1 para o P2 (1.841,17 versus 1.377,92 x $10^{6}$ sptz/mL, $\mathrm{P}<0,05$ ). Contudo, não houve diferença
$(\mathrm{P}>0,05)$ nos valores apresentados pelos animais de CONT e ÓLEO dentro de cada período.

Foram encontradas correlações significativas negativas entre triglicerídeos e defeitos menores $(\mathrm{r}=-0,412 ; \quad \mathrm{P}=0,006)$, LDL e defeitos totais $(\mathrm{r}=-0,333 ; \mathrm{P}=0,030)$, lipídios totais e defeitos menores $(\mathrm{r}=-0.366 ; \mathrm{P}=0,017)$ e lipídios totais e defeitos totais $(r=-0.309 ; \mathrm{P}=0,046)$, enquanto a correlação entre VLDL e viabilidade espermática foi positiva $(\mathrm{r}=0,381 ; \mathrm{P}=0,012)$. 


\section{DISCUSSÃO}

Os consumos médios diários de matéria seca, matéria seca por peso vivo e proteína foram praticamente idênticos entre grupos. Esse efeito era esperado, pois a concentração de extrato etéreo das rações formuladas, supostamente, não inibiria o consumo, mesmo com a adição do óleo de palma. Contudo, a ingestão de ácidos graxos no Grupo ÓLEO foi superior, em função da maior concentração de extrato etéreo na composição da dieta. Por isso, em termos absolutos, houve maior consumo de ácidos graxos insaturados no Grupo ÓLEO (479,97 versus $308,75 \mathrm{~g} / \mathrm{animal} / \mathrm{dia})$, com elevação de consumo da ordem de 55,44\%. Para os ácidos graxos saturados, a elevação de consumo foi de $71,23 \%$ nos animais tratados (132,07 versus $77,14 \mathrm{~g} / \mathrm{animal} / \mathrm{dia})$.

Independentemente dos períodos, o consumo de óleo de palma elevou as taxas séricas de lipídios totais, colesterol e HDL, sem, contudo, influenciar as concentrações de triglicerídeos, LDL e VLDL. As concentrações de colesterol sérico foram superiores às encontradas em touros bubalinos por Nalavade et al. (2002), de $49,08 \pm 2,01 \mathrm{mg} / \mathrm{dL}$, mas inferiores às encontradas em novilhas bubalinas por Gandra et al. (2011), de $102,3 \mathrm{mg} / \mathrm{dL}$. Maiores taxas séricas de colesterol influenciam suas concentrações no plasma seminal e reduzem o processo de capacitação espermática precoce, por inibir os rearranjos de fosfolipídios e colesterol e, consequentemente, a reação acrossômica (Travis e Kopf, 2002). Sabe-se que, durante a capacitação espermática, o colesterol é um importante marcador da qualidade seminal, devido a seu efluxo, sendo que o influxo de colesterol inibe a reação acrossômica e, consequentemente, a fecundação (Moreau e Manjunath, 2000). Uma vez que as concentrações de lipídios detectados no sangue e no plasma seminal, entre eles o colesterol, têm relação direta com a fertilidade de touros (BeerLjubic et al., 2009), diferenças nos parâmetros seminais dos touros bubalinos alimentados com adição do óleo de palma eram esperadas.

Os valores séricos de HDL do Grupo CONT corroboram os achados de Gandra et al. (2011), que observaram $33,70 \mathrm{mg} / \mathrm{dL}$ em novilhas bubalinas alimentadas com silagem de milho e concentrado. $\mathrm{O}$ enriquecimento da dieta com óleo de palma, além de oferecer maior densidade energética, foi capaz de elevar em aproximadamente $21 \%$ as concentrações de HDL ( $\mathrm{P}<0,05)$. Segundo Nikam et al. (2005), elevação do HDL sérico em touros bubalinos das raças Surti e Murrah promovem elevação de HDL também no plasma seminal, com concentrações detectadas de $12,95 \pm 1,95$ e $16,04 \pm 0,76 \mathrm{mg} / \mathrm{dL}$, respectivamente. Os perfis bioquímicos séricos de LDL não diferiram $(\mathrm{P}>0,05)$ entre grupos, sendo distintos dos resultados de Gandra et al. (2011), que observaram 60,04mg/dL em novilhas bubalinas, evidenciando o efeito do manejo alimentar e diferenças metabólicas sobre as concentrações de LDL. Estudos prévios comprovaram que o LDL promove a incorporação e impede a saída de fosfolipídios e colesterol da membrana espermática, pela formação de um complexo com as proteínas BSP do plasma seminal. Dessa forma, maiores concentrações de LDL sérico poderiam elevar seu teor no plasma seminal e, por sua ação, conferir às células maior resistência ao choque térmico, impedindo que as proteínas do plasma seminal fiquem disponíveis para atuar na membrana espermática, evitando o efluxo de fosfolipídios e colesterol (Bergeron e Manjunath, 2006). Contudo, a ausência de diferença significativa do LDL sugere que a incorporação de óleo de palma na dieta, pelo menos na concentração estudada ( $2 \%$ da $\mathrm{MS})$, não modificaria as concentrações de LDL no plasma seminal.

Os valores de VLDL sérico não diferiram $(\mathrm{P}>0,05)$ entre grupos e estão abaixo dos parâmetros encontrados por Gandra et al. (2011) (6,56mg/dL) e Ranjan et al. (2012) $(16,27 \mathrm{mg} / \mathrm{dL})$, estes últimos tendo fornecido gordura protegida para fêmeas bubalinas em lactação. A presença de receptores para VLDL em espermatozoides sugere que estes utilizam lipídios extracelulares, estando o papel desses receptores associado ao prolongamento da utilização de energia e ao provimento para o espermatozoide de metabólitos essenciais, tais como triglicérides, fosfolípides e ácidos graxos (Argov et al., 2007), com maior eficiência na utilização de energia. Estruturalmente, o VLDL também pode favorecer os espermatozoides, ao atuar na substituição dos ácidos graxos saturados por insaturados, para a produção de uma membrana plasmática mais maleável e resiliente. Essas características são interessantes para elevar 
a eficiência da criopreservação celular, quando há expressiva passagem de fluidos pela membrana plasmática e incremento no volume celular. De fato, a correlação entre VLDL e viabilidade espermática $(\mathrm{r}=0,381 ; \quad \mathrm{P}=0,012)$ corrobora essa teoria, confirmando que, quanto maior a quantidade sérica de VLDL, maior a integridade física da membrana plasmática dos espermatozoides, característica especificamente avaliada pelo teste de coloração por eosinanigrosina (Arruda et al., 2010).

As concentrações séricas de lipídios totais no Grupo ÓLEO foram superiores às do Grupo CONT, fato que pode ser atribuído essencialmente à alimentação. Entretanto, os dados observados foram distintos dos previamente publicados para touros bubalinos, de $213,26 \mathrm{mg} / \mathrm{dL}$ e $324,74 \pm 3,81 \mathrm{mg} / \mathrm{dL}$ (Ranjan et al., 2012; Nalavade et al., 2002). Sob esse prisma, incrementos nos lipídios séricos totais, caso associados a um aumento paralelo nas concentrações de lipídios totais no plasma seminal, como ocorre em bovinos (Beer-Ljubic et al., 2009), poderiam representar uma ameaça à integridade da membrana espermática. Isso porque, se por um lado a adição de óleo à dieta é benéfica às células espermáticas devido aos efeitos diretos do colesterol e do VLDL no processo de capacitação espermática e na maior fluidez das membranas celulares, respectivamente, eventual incremento dos lipídios no plasma seminal poderia elevar as taxas de peroxidação lipídica no sêmen por ação das espécies reativas de oxigênio (ROS), comprometendo a função das membranas celulares. Os valores encontrados no teste hiposmótico confirmaram redução na integridade de membrana do sêmen em animais alimentados com dieta enriquecida com óleo de palma.

De modo interessante, mesmo que a elevação dos lipídios totais fosse suficiente para predispor as células à peroxidação lipídica, esse evento não teria apresentado reflexos na morfologia espermática. As correlações negativas e de média intensidade obtidas entre lipídios totais, triglicerídeos e LDL com defeitos espermáticos sugerem o oposto, ou seja, que houve efeitos benéficos da maior lipidemia na morfologia seminal, uma das características que mais se correlaciona com fertilidade (Arruda et al., 2011). De fato, se a maior concentração lipídica favorece as espermatogônias durante a fase inicial de gametogênese e é necessária nos processos de meiose e diferenciação dos espermatócitos (Schenk e Hoeger, 2010), justifica-se o menor valor de defeitos totais.

Recentemente, descobriu-se que o consumo de ácidos graxos saturados é negativamente relacionado à concentração espermática em humanos (Attaman et al., 2012). É possível que esta segunda situação também ocorra em machos bubalinos, uma vez que foi observada no Grupo ÓLEO menor relação AGI/AGS (3,63 versus 4,0), maior consumo diário de AGS e redução da concentração espermática média ao longo do tempo. Contudo, diferentemente dos humanos, a redução observada na concentração espermática no presente trabalho foi discreta, e o sêmen se manteve dentro dos parâmetros fisiológicos para touros bubalinos adultos (Vale, 2002).

Em relação ao efeito do tempo no perfil lipídico sérico, maiores concentrações de VLDL no P1 refletem o aumento da metabolização lipídica para as células-alvo, devido à maior oferta de ácidos graxos, superior àquela imediatamente necessária para metabolização, fazendo com que no P2 ocorresse aumento nas concentrações de lipídios totais e colesterol, com deposição de lipídios nos órgãos de reserva. Esse fato pode ser confirmado; pois, com o aumento da metabolização lipídica, a concentração de LDL foi elevada significativamente no P2, o que aumenta a oferta de colesterol para os tecidos, inclusive os reprodutivos.

Além dos efeitos nutricionais, os lipídios desempenham funções estruturais e de regulação celular, tendo importante influência nas funções fisiológicas, de modo que não podem ser considerados apenas como uma fonte de energia. Os ácidos graxos poli-insaturados (PUFAs), principalmente os pertencentes aos grupos ômega-3 ( $\omega 3)$ e ômega-6 ( $\omega 6)$, são potentes mediadores intracelulares e intercelulares, sendo precursores para a síntese dos eicosanoides, e moduladores da rede de sinalização celular e da fluidez das membranas (Pompeia et al., 2000). Os fosfolipídios das membranas espermáticas de mamíferos contêm caracteristicamente proporções elevadas de ácidos graxos poli-insaturados de cadeia longa (C:22), particularmente série $\omega-3$ (Dolatpanah et al., 2008). Uma vez que a quantidade de PUFAs consumida determina diferentes proporções dos 
mesmos na composição da membrana espermática (Maldjian et al., 2005) e que os ácidos graxos $\omega 3$ e $\omega 6$ são os principais PUFAs encontrados nos espermatozoides de búfalos, representando mais de $70 \%$ do total dos ácidos insaturados (Jain e Anand, 1976), o maior consumo de $\omega 3$ e $\omega 6$ em bubalinos pode ser benéfico à qualidade seminal. A julgar pelo consumo mais elevado de $\omega 3$ e $\omega 6$ no Grupo ÓLEO, impactos sobre o perfil lipídico e na qualidade seminal eram esperados. Contudo, não foram constatadas diferenças estatísticas significativas entre os Grupos CONT e ÓLEO para as variáveis seminais, salvo no turbilhonamento e na integridade de membrana.

A motilidade espermática progressiva não apresentou diferença estatística entre grupos. Provavelmente, a quantidade de ácidos graxos poli-insaturados 22:6n-3, um importante componente dos fosfolipídios e que possui relação com a motilidade (Dolatpanah et al., 2008), seja equivalente nos Grupos CONT e ÓLEO, mas o referido ácido graxo não foi investigado no presente trabalho. Os animais do Grupo CONT apresentaram turbilhonamento superior aos do Grupo ÓLEO, devido à redução da concentração espermática, no P2. Ao analisar os demais dados seminais dos touros bubalinos, como o volume espermático, $\mathrm{pH}$ seminal, motilidade progressiva, vigor, viabilidade espermática e defeitos totais, observa-se que estão de acordo com os dados fisiológicos previamente publicados (Vale, 2002), sendo constatado que não houve efeito da suplementação com óleo de palma sobre esses parâmetros seminais.

\section{CONCLUSÕES}

A introdução de $2 \%$ de óleo de palma na MS da dieta oferecida a touros bubalinos em confinamento alterou o perfil lipídico sérico e não reduziu a qualidade do sêmen de touros bubalinos a valores abaixo dos fisiológicos. A maior lipidemia, independentemente da fonte de ácidos graxos, favoreceu a morfologia espermática e apresentou associação positiva com a viabilidade dos espermatozoides. Contudo, o uso de óleo de palma na dieta per se não elevou parâmetros seminais que pudessem estar relacionados ao potencial de fertilidade dos touros.

\section{AGRADECIMENTOS}

À equipe do Laboratório de Medidas Físicas (UFPA) e à da Fábrica de Rações (UFRA) pelo apoio na execução do trabalho. À Embrapa (Rede BIOTEC, códigos 0107010204 e 0107010203), à CAPES e ao CNPq pelo suporte financeiro e bolsas de estudo.

\section{REFERÊNCIAS}

ADEEL, M.; IJAZ, A.; ALEEM, M. et al. Improvement of liquid and frozen-thawed semen quality of Nili-Ravi buffalo bulls (Bubalus bubalis) through supplementation of fat. Theriogenology, v.71, p.1220-1225, 2009.

ARGOV, N.; SKLAN, D.; ZERON, Y.; ROTH, $Z$. Association between seasonal changes in fatty-acid composition, expression of VLDL receptor and bovine sperm quality. Theriogenology, v.67, p.878-885, 2007.

ARRUDA, R.L.; ORRO, I.R.; PASSOS, T.S. et al. Técnicas para avaliação laboratorial da integridade estrutural e funcional do sêmen congelado de touros. Rev. Bras. Reprod. Anim., v.34, p.168-184, 2010.

ARRUDA, R.P.; CELEGHINI, E.C.C.; ALONSO, M.A. et al. Métodos de avaliação da morfologia e função espermática: momento atual e desafios futuros. Rev. Bras. Reprod. Anim., v.35, p.145-151, 2011.

ATTAMAN, J.A.; TOTH, T.L.; FURTADO J. et al. Dietary fat and semen quality among men attending a fertility clinic. Hum. Reprod., v.27, p.1466-1474, 2012.

BEER-LJUBIC, B.; ALADROVIC', J.; MARENJAK, T.S. et al. Cholesterol concentration in seminal plasma as a predictive tool for quality semen evaluation $\mathrm{I}$. Theriogenology, v.72, p.1132-1140. 2009.

BERGERON, A.; MANJUNATH, P. New insights towards understanding the mechanisms of sperm protection by egg yolk and milk. Mol. Reprod. Dev., v.73, p.1338-1344, 2006.

BLIGH, E.G.; DYER, W.J. A rapid method for total lipid extraction and purification. Can. J. Biochem. Physiol., v.37, p.911-917, 1959. 
BLOM, E. The ultrastructure of some characteristics sperm defects and a proposal for a new classification on the bull spermiogram. Nord. Vet. Med., v.25, p.383-391, 1973.

DOLATPANAH, M.B.; TOWHIDI, A.; FARSHAD, A. et al. Effects of dietary fish oil on semen quality of goats. Asian-Austral. J. Anim., v.21, p.29-34, 2008.

FRIEDEWALD, W.T.; LEVY, R.L.; FREDRICKSON, D.L. Estimation of the concentration of low-density lipoprotein cholesterol in plasma, without use of the preparative ultracentrifuge. Clin. Chem., v.18, p.499-502, 1972.

GANDRA, J.R.; FREITAS JUNIOR, J.E.; BARLETTA, R.V. et al. Productive performance, nutrient digestion and metabolism of Holstein (Bos taurus) and Nellore (Bos taurus indicus) cattle and Mediterranean Buffaloes (Bubalus bubalis) fed with corn-silage based diets. Livest. Sci., v.140, p.283-291, 2011.

IQBAL, M.; ALEEM, M.; IJAZ, A. et al. Assessment of buffalo semen with the 3-(4,5dimethylthiazol-2-yl)-2,5-diphenyltetrazolium bromide reduction assay. J. Anim. Sci., v.88, p.922-925, 2010.

JAIN, Y.C; ANAND, S.R. Fatty acids and fatty aldehydes of buffalo seminal plasma and sperm lipid. J. Reprod. Fertil., v.47, p.261-267, 1976.

KHAN M.I.R.; IJAZ, A. Effect of osmotic pressure on motility, plasma membrane integrity and viability in fresh and frozen-thawed buffalo spermatozoa. Animal, v.2, p.548-553, 2008.

MALDJIAN, A.; PIZZI, F.; GLIOZZI, T. et al. Changes in sperm quality and lipid composition during cryopreservation of boar semen. Theriogenology, v.15, p.411-421, 2005.

MOREAU, R.; MANJUNATH, P. Characteristics of the cholesterol efflux induced by novel seminal phospholipid-binding proteins. Biochim. Biophys. Acta, v.1487, p.24-32, 2000.

NALAVADE, S.B.; TALVELKAR, B.A.; DESHMUKH, B.T. et al. Comparative study of blood serum lipid profile in buffalo and cow bulls. J. Bomb. Vet. Coll., v.10, p.15-18, 2002.
NIKAM, S.R.; DESHMUKH, B.T.; VADNERE, N.B. et al. Comparative appraisal of seminal plasma lipid profile in buffalo and cow bulls. $J$. Bomb. Vet. Coll., v.13, p.46-49, 2005.

PAUL, S.S.; LAL, D. Nutrient requirements of buffaloes. India: SSPH, 2010.137p.

POMPEIA, C.; LOPES, L.R.; MIYASAKA, C.K. et al. Effect of fatty acids on leukocyte function. Braz. J. Med. Biol. Res., v.33, p.12551268, 2000.

RANJAN. A.; SAHOO, B.; SINGH, V.K. et al. Effect of bypass fat supplementation on productive performance and blood biochemical profile in lactating Murrah (Bubalus bubalis) buffaloes. Trop. Anim. Health. Prod., v.44, p.1615-1621, 2012.

RODRIGUES, A.M.C.; DARNET, S.; SILVA, L.H.M. Fatty acid profiles and tocopherol contents of buriti (Mauritia flexuosa), patawa (Oenocarpus bataua), tucuma (Astrocaryum vulgare), mari (Poraqueiba paraensis) and inaja (Maximiliana maripa) fruits. J. Brazil. Chem. Soc., v.21, p.2000-2004, 2010.

STATISTICAL Analysis Sistem. SAS INSTITUTE. SAS/STAT User's guide: statistics. 4 ed. Version 6, Cary, NC: v.2. 1993. 943p.

SCHENK, S.; HOEGER, U. Lipid accumulation and metabolism in polychaete spermatogenesis: Role of the large discoidal lipoprotein. Mol. Reprod. Dev., v.77, p.710-719, 2010.

SHARMA, A.K; GUPTA, R.C. Duration of seminiferous epithelial cycle in buffalo bulls (Bubalus bubalis). Anim. Reprod. Sci., v.3, p.217-224, 1980.

TRAVIS, A.J.; KOPF, G.S. The role of cholesterol efflux in regulating the fertilization potential of mammalian spermatozoa. J. Clin. Invest., v.110, p.731-736, 2002.

VALE, W.G. Reproductive management of buffalo male aiming semen production for artificial insemination. In: BUFFALO SYMPOSIUM OF AMERICAS, 1., 2002, Belém. Proceedings... Belém: APCB. 2002. p.156-171. 